\title{
UMA VOZ \\ ESTRUTURANTE E GNÔMICA EM FEUX, DE MARGUERITE YOURCENAR ${ }^{1}$ Mônica KALIL ${ }^{2}$
}

RESUMO: Às diferentes vozes que atuam explicitamente nos níveis textual e paratextual da obra Feux (1936), da escritora francesa Marguerite Yourcenar, soma-se outra, com função estruturante e gnômica. A autora cria uma espécie de mise en abyme de vozes, em um jogo de desarticulação e desestabilização enunciativa entre a "voz que existe e a voz que vem e que deve vir", nos termos de Paul Valéry, garantindo seu efeito de produção poética.

PALAVRAS-CHAVE: Marguerite Yourcenar, Feux, voz.

\footnotetext{
${ }^{1} \mathrm{O}$ presente artigo apresenta resultados parciais de pesquisa em andamento para dissertação de mestrado.

${ }^{2}$ Mestranda em Estudos da Tradução, FFLCH/USP, monica.kalil@usp.br.
} 


\section{A STRUCTURING AND GNOMIC VOICE IN FEUX, BY MARGUERITE YOURCENAR}

ABSTRACT: In addition to the different voices explicitly working both on the textual and the paratextual levels of Feux (1936), by French writer Marguerite Yourcenar, there is another one, playing a structuring and gnomic role. The author creates a sort of mise en abyme of voices, in an enunciation game of disruption and destabilization between the "voice there is and the voice that is coming and must come," in the words of Paul Valéry, thus ensuring its effect of poetic production.

KEYWORDS: Marguerite Yourcenar, Feux, voice.

\section{« J'ESPÈRE QUE CE LIVRE NE SERA JAMAIS LU » ${ }^{3}$}

Feux, obra da escritora francesa de origem belga Marguerite Yourcenar, foi iniciada em 1935 e publicada em 1936, tendo sido republicada em 1957 quase sem nenhuma alteração. Em seu prefácio, a própria autora a define como uma coleção de poemas de amor em prosa poética entremeados por pensamentos originados nas anotações de um diário íntimo. Conforme observa Bruno Chiron (1993), os termos "romance" ou "ensaio" não são utilizados para qualificar a obra, preferindo a autora se posicionar no campo poético ou lírico.

Segundo Anne-Marie Prévot, a respeito de Marguerite Yourcenar,

é forçoso constatar que o público construiu a imagem de uma mulher que se caracterizava por certa frieza, por um distanciamento em relação ao outro [...]. Como escritora, o epíteto de 'clássica' é associado a ela com frequência a partir da leitura de obras como Memórias de Adriano e A obra em negro, por exemplo, que parecem não refletir senão um mundo de ideias e palavras perfeitamente dominadas, ordenadas, um conteúdo solidamente apoiado em pesquisas históricas, em uma cultura imensa. ${ }^{4}$ (PRÉVOT, 2002, p. 11)

Fruto de uma crise passional vivida por Yourcenar, Feux traz nove textos em que a autora lança mão de personagens míticos ou reais todos da Antiguidade

\footnotetext{
3 "Espero que este livro jamais seja lido". (YOURCENAR, 1974, p. 29) Obs.: Todas as traduções são nossas.

${ }^{4}$ « [...] force est de constater que le public a construit l'image d'une femme qui se caractérisait par une certaine froideur, une distance entretenue avec autrui [...]. En tant qu'écrivain, l'épithète "classique" lui est fréquemment associée à partir de la lecture d'œuvres comme Mémoires d'Hadrien, L'œuvre au noir, par exemple, qui semblent ne refléter qu'un monde d'idées et de mots parfaitement maîtrisés, ordonnés, un contenu solidement arrimé à des enquêtes historiques, à une culture immense. "
} 
clássica, à exceção de Maria Madalena para abordar a paixão em seus mais diversos aspectos, dos mais carnais aos mais transcendentes, de modo a universalizá-los. Os pensamentos que separam os textos trazem reflexões ora precisas, ora enigmáticas, mas sempre repletas de lirismo, marcadamente na voz de um eu poético. Os textos colocam lado a lado elementos do sagrado e do profano, sendo ainda permeados por influências artísticas e elementos da contemporaneidade da escritora no período entreguerras da primeira metade do século XX. Segundo Sophie Galabru (2013), essa "superposição do passado ao moderno, ou seja, o mito e sua expressão contemporânea" foi uma constante entre diversos autores e artistas dos anos 1930-1940.

De acordo com Sue Lonoff de Cuevas (2008), as obras de ficção de Marguerite Yourcenar anteriores à Segunda Guerra Mundial, como Alexis ou o tratado do vão combate e Golpe de misericórdia, além de certos trechos de Denário do sonho, "exploravam uma sensualidade perturbadora"6 (CUEVAS, 2008, p. 17), um amor sempre unilateral. Seria esse também o caso de Feux, fruto de uma crise originada a partir da paixão não correspondida de Yourcenar por seu então editor, André Fraigneau, "indiferente a seu sofrimento" (CUEVAS, 2008, p. 13). A esse elemento pessoal desencadeador, uniu-se outra de suas paixões: o estudo da cultura e da mitologia grega. Ainda que subvertendo a definição clássica da arte poética, em que tudo era técnica, em que não havia a noção romântica da expressão do sentimento, Yourcenar escolhe a res e a uerba clássicas por excelência seu tema são os mitos e sua palavra é sublime para "glorificar um amor bastante concreto, ou talvez para exorcizá-lo", associando visivelmente "a idolatria do ser amado [...] a paixões mais abstratas, mas não menos intensas, que predominam às vezes sobre a obsessão sentimental e carnal”8 (YOURCENAR, 1974, p. 26).

Embora o livro se inicie com um desejo expresso "J'espère que ce livre ne sera jamais lu »(YOURCENAR, 1974, p. 29) ， a edição de 1957 é acrescida de um prefácio autoral, em 1967, em que Yourcenar expõe sua motivação para a reescritura de mitos antigos segundo um olhar apaixonado e modernizante e descreve longamente suas características estilísticas ou temáticas, ainda que secundárias diante de sua inspiração passional. Nele, a autora admite que "a franqueza arrogante da pessoa que fala em Feux, com ou sem máscara, a vontade insolente de se dirigir apenas ao leitor já adquirido ou conquistado, representa uma recusa a certos compromissos eruditos e superficiais"” (YOURCENAR, 1974, p. 15).

\footnotetext{
5 « [...] superposant le passé au moderne, c'est-à-dire le mythe et son expression contemporaine [...]. »

« [...] explorant une sensualité troublante. »

7 « [...] indifférent à ses souffrances. »

8 « [...] glorifier un amour très concret, ou peut-être exorciser celui-ci [...] », « [...] l'idolâtrie de l'être aimé s'associe [...] à des passions plus abstraites, mais non moins intenses, qui prévalent parfois sur l'obsession sentimentale et charnelle [...]. »

"La franchise arrogante de la personne qui parle dans Feux, avec ou sans masques, l'insolente volonté de ne s'adresser qu'au lecteur déjà acquis ou conquis représentent un roidissement contre certains compromis savants et légers. »
} 
Historicamente, o sucesso da reescritura desses mitos sempre foi favorecido pela explícita centralidade que a Antiguidade Clássica ocupa nos diversos polissistemas literários, diacrônica ou sincronicamente, qualquer que seja a perspectiva, dentro de uma canonicidade dinâmica, em que certos modelos literários se estabelecem como princípio produtivo no sistema, conforme a Teoria dos Polissistemas de Even-Zohar, da Escola de Telavive.

Podemos classificar o conjunto dos textos em prosa poética de Feux como uma retradução, já que foi produzido a partir de uma poética da oralidade tantas vezes escrita e reescrita ao longo dos séculos, com adaptações já na Antiguidade para gregos e romanos, além de incontáveis releituras e interpretações há milênios.

Ao incluir um prefácio a essa série de retraduções poéticas, Yourcenar projeta sua pena, marcando posição para que nada escape, na interpretação do leitor, daquilo que há de inovação, de modernização e de influência em sua criação literária. Tendo escrito originalmente esse livro para que "não fosse lido", segundo seu próprio desejo expresso, Yourcenar parece ter sentido a necessidade antes, a urgência de evitar qualquer possibilidade de invisibilidade no espírito de que estava imbuída, procurando deixar expressa sua releitura dos mitos.

Yourcenar declara que seus textos modernizam o passado, impregnando a Antiguidade com diversas influências artísticas e com a contemporaneidade do início do século XX, especialmente do período entreguerras. Sua Fedra não é a Fedra ateniense, mas aquela que conhecemos de Racine. Aquiles e Pátroclo são vistos menos sob a ótica homérica que sob um olhar onírico com influência de outros poetas, pintores e escultores. O pano de fundo para sua Antígona é carregado dos dramas de guerra civil e de antecipação de nova guerra mundial vividos nos anos 1930. A guerra civil e a cor local também emprestam à história de Lena ares da contemporaneidade. A cena de Aquiles e Misandra descendo as escadas encontra espelho nos espetáculos protagonizados pelo transformista norte-americano Barbette em tempos surrealistas. Cocteau, Diaghileff, Massine são todos referências contemporâneas à autora, inspirando imagens a se mesclarem aos mitos do passado. Yourcenar expõe o condicionamento da obra a seu tempo: "Tout livre porte son millésime et il est bon qu'il le fasse ${ }^{10}$ (YOURCENAR, 1974, p. 13). Adota, assim, um fazer tradutório inovador e atualizador em sua obra, assumindo todas as influências de seu meio e de sua época, refletindo a cena político-social do período entreguerras e a cena artística, marcada pela paixão por espetáculos de balé, música e filme.

Conforme Dominique Maingueneau (2001, p. 126), "as obras podem basear sua cenografia em cenários já validados”, não no sentido de "valorizado[s], mas já instalado[s] no universo de saber e de valores do público". Para ele,

não é necessário que a situação de enunciação "mostrada" pela obra esteja em conformidade perfeita com os cenários validados que ela reivindica em seu texto, nem que as últi-

10“Todo livro traz a marca de seu tempo e é bom que o faça." 
mas formem um conjunto homogêneo. A cenografia global da obra resulta de fato do relacionamento de todos esses elementos, do percurso de sua rede (MAINGUENEAU, 2001, p. 127).

A respeito de textos que percorrem uma rede de lugares com alto nível de validação, Maingueneau caracteriza-os como

lugares que são também tempos: a convocação de lugares enunciativos inspirados na Antiguidade greco-romana, na Bíblia, na história contemporânea, supõe a presença envolvente de um cosmos barroco, onde a diversidade das épocas e dos espaços oferece-se ao olhar do leitor na simultaneidade de um quadro (MAINGUENEAU, 2001, p. 130).

Podemos interpretar essa mescla entre antiguidade e contemporaneidade a partir de um dos pensamentos "J'ai beau changer : mon sort ne change pas. Toute figure peut être inscrite à l'intérieur d'un cercle. "11 (YOURCENAR, 1974, p. 30) e à luz de Anatol Rosenfeld (ROSENFELD, 1965), ao falar da atemporalidade e da circularidade do tempo mítico em contraste com a linearidade e a progressividade do tempo judaico-cristão. Yourcenar nos transporta ao tempo da Antiguidade clássica, com seus personagens marcados por uma sorte inescapável, por um destino já determinado. Na dimensão mítica, o tempo é circular: passado, presente e futuro se fundem. É um tempo em que tudo se integra, em que tudo pode fazer sentido. E, no caso de Feux, nessa circularidade, multiplicam-se e ecoam diversas vozes.

\section{« JE TE PARLE À VOIX BASSE, CAR C'EST SEULEMENT LORSQUE NOUS PARLONS À VOIX BASSE QUE NOUS NOUS ÉCOUTONS NOUS- MÊMES. " ${ }^{12}$}

As nove histórias são entremeadas por dez grupos de pensamentos que sugerem uma persona, conforme Frederick Farrell e Edith R. Farrell (1982), expondo escritos de um diário íntimo, todos de um sujeito poético em primeira pessoa manifestandose a partir de uma voz autoral central a revelar seu estado de alma, com reforços expressivos formais e semânticos contidos em textos breves, de curta extensão.

Farrell e Farrell (1982) identificam, no conjunto de textos e pensamentos de Feux, um mergulho em si mesmo e a posterior volta, em um efeito que poderia ser

\footnotetext{
11“Por mais que eu mude, minha sorte não mudará. Toda figura pode ser inscrita no interior de um círculo."

12،Falo-te em voz baixa porque somente quando falamos em voz baixa é que escutamos a nós mesmos." (YOURCENAR, 1974, p. 186)
} 
representado como "uma curva em sino invertida"13 (FARRELL \& FARRELL, 1982, p. 4), acompanhando uma alegria inicial que se transforma em doloroso desespero para finalmente alcançar aceitação e transcendência (FARRELL \& FARRELL, 1982, p. 2). Segundo eles, "para causar essa impressão, a autora estruturou cuidadosamente o livro, distribuindo e equilibrando seus componentes [os nove textos] de forma que a segunda metade ecoasse e espelhasse a primeira, mas com uma ênfase mais positiva" ${ }^{14}$ (FARRELL \& FARRELL, 1982, p. 4). Os pensamentos entremeados aos textos sustentam o equilíbrio e a simetria,

apresentam questionamentos, tecem comentários a respeito da história precedente, preparam o leitor para a história que virá, e oferecem ligações temáticas entre os textos. Contam uma história por si só, mas não são originalmente narrativos. São usados para destacar, por meio de passagens líricas, ironias, mudanças bruscas de tom, etc., o sentido que se pode perder nos textos caso o leitor fique por demais envolvido com suas especificida$\operatorname{des}^{15}$ (FARRELL \& FARRELL, 1982, p. 16).

Interessa-nos, assim como tantas outras, a voz dessa persona dos pensamentos, especialmente se observarmos a produção da obra Feux como um conjunto paratópico de uma mise en abyme de vozes - Yourcenar escritora, Yourcenar autora de Feux, Yourcenar persona, Yourcenar gnômica -, como veremos adiante.

Há, simultaneamente, um contraponto e um paralelo entre o que poderíamos chamar de a voz de "Yourcenar autora de Feux", que se impõe no prefácio, e a voz de "Yourcenar persona", expressa nos pensamentos a costurar as nove histórias. Contraponto na medida em que "Yourcenar autora de Feux" procura estabelecer uma objetividade e uma racionalidade que contrastam com a subjetividade e o caráter passional de "Yourcenar persona"; paralelo quando observamos que esta voz estrutura o encadeamento dos textos assim como aquela indica uma determinada leitura da obra.

Conforme Gérard Genette, ao incluir um prefácio original, que "consiste numa interpretação do texto pelo autor, ou, se preferir, numa declaração de intenção" (GENETTE, 2009, p. 196), Yourcenar expõe detalhadamente aspectos estilísticos e temáticos, embora silencie sobre a questão passional desencadeadora do livro, possivelmente como forma de autopreservação ou proposta de universalização de

\footnotetext{
13 "[...] an inverted bell-shaped curve."

14 "To achieve this impression, the author has carefully structured the book, distributing and balancing its components so that the second half echoes and mirrors the first half, but has a more positive emphasis."

15 "[...] pose questions, comment on the previous story, prepare the reader for the one to come and provide thematic links among the tales. They tell a story in themselves, but they are not primarily narrative. They are used to point up, by lyric passages, irony, sudden shifts in tone, etc., the meaning that can be lost in the tales should the reader become too involved with their specifics."
} 
um amor que, na origem, era particularizado. Daí, certamente, a escolha temática do mito e sua linguagem arquetípica.

\section{«CASSANDRE HURLAIT SUR LES MURAILLES, EN PROIE À L'HORRIBLE TRAVAIL D'ENFANTER L'AVENIR. . ${ }^{16}$}

Em entrevista a Matthieu Galey, diante da afirmativa de que, em seus livros, Marguerite Yourcenar estava sempre escondida atrás de homens para oferecer sua visão de mundo, "Yourcenar escritora" responde: "Escondida? Esse termo me deixa escandalizada. Mas, de qualquer maneira, não em Feux, onde é quase continuamente uma mulher que fala" ${ }^{\prime 17}$ (YOURCENAR 1980, p. 270).

Para além da hipótese de Farrel e Farrell (1982) da função estrutural da voz de "Yourcenar persona" por meio dos pensamentos, podemos observá-la ainda mesclada aos textos em enunciados gnômicos, ou seja, proferindo verdades absolutas ou omnitemporais.

É assim que, no texto dedicado a Clitemnestra, por exemplo, narrado em primeira pessoa, temos «Messieurs les Juges, il n'y a qu'un homme au monde : le reste n'est pour chaque femme qu'une erreur ou qu'un pis-aller triste. Et l'adultère n'est souvent qu'une forme désespérée de la fidélité » ${ }^{18}$ (YOURCENAR, 1974, p. 179-180) ou "Moi aussi, Messieurs les Juges, je savais l'avenir. Toutes les femmes le savent : elles s'attendent toujours à ce que tout finisse mal ${ }^{19}$ (YOURCENAR, 1974, p. 186).

Em "Antígona ou a escolha", lemos "On ne tue pas la lumière; on ne peut que la suffoquer $\gg^{20}$ (YOURCENAR, 1974, p. 82); em "Maria Madalena ou a salvação", " on ne fait jamais que changer d'esclavage » ${ }^{21}$ (YOURCENAR 1974, p. 125); em "Fédon ou a vertigem", "Car les vertus, Cébès, n’ont pas toutes les mêmes causes et toutes ne sont pas belles " ${ }^{22}$ (YOURCENAR, 1974, p.150) e "Pour ceux qui aiment, le temps n'est plus [...]. Pour ceux qui souffrent, le temps n'est pas ${ }^{23}$ (YOURCENAR, 1974, p. 141-142); ou, ainda, em "Safo ou o suicídio", « Mais ceux

\footnotetext{
16“"Cassandra gritava sobre as muralhas, assolada pelo terrível trabalho de dar à luz o futuro." (YOURCENAR, 1974, p. 162)

${ }_{7}$ "Cachée? Le mot me scandalise. Pas dans Feux, en tout cas, où c'est presque continuellement une femme qui parle. »

18 "Senhores Juízes, não há senão um único homem no mundo: todos os outros, para cada mulher, não são mais que um erro ou uma triste alternativa. E o adultério não costuma ser nada mais que uma forma desesperada de fidelidade."

19 "Eu também, Senhores Juízes, podia adivinhar o futuro. Todas as mulheres podem: elas sempre preveem que tudo acabará mal."

20"Não se pode extinguir a luz; não se pode senão sufocá-la."

21 "Não fazemos outra coisa senão trocar de escravidão."

22"Pois as virtudes, Cebes, não possuem todas as mesmas causas nem são todas belas."

23 "Para aqueles que amam, o tempo deixa de existir [...]. Para aqueles que sofrem, o tempo não existe."
} 
qui manquent leur vie courent aussi le risque de rater leur suicide ${ }^{24}$ (YOURCENAR, 1974, p. 215).

Essa mesma voz gnômica faz, vez por outra, referências a temas expostos nos pensamentos, como "L'alcool dégrise. Après quelques gorgées de cognac, je ne pense plus à toi »25 (YOURCENAR, 1974, p. 30). Mais adiante, em "Lena ou o segredo", temos «ivre d'une ivresse qu'elle espérait pouvoir attribuer à l'alcool, car on se corrige du vin plus vite que du bonheur ${ }^{26}$ (YOURCENAR, 1974, p. 92). Outro exemplo é o pensamento "Je suis près du noyau mystérieux des choses comme la nuit on est quelquefois près d'un cœur» ${ }^{27}$ (YOURCENAR, 1974, p. 92), que nos remete a «Le pendule du monde est le cœur d'Antigone» ${ }^{28}$, frase que encerra "Antígona ou a escolha".

\section{«IL ARRIVE TOUJOURS UN MOMENT OÙ L'ON APPREND À SE TAIRE, PEUT-ÊTRE PARCE QU'ON EST ENFIN DEVENU DIGNE D'ÉCOUTER. $~^{29}$}

Paul Valéry, em sua aula inaugural do curso de Poética no Collège de France, em 10 de dezembro de 1937, trata da produção poética como "obra do espírito", entregando à sua materialidade uma dimensão sensível, aquela do imponderável, do aludido, do invocado, a garantir o mistério que diferencia a linguagem poética da linguagem cotidiana, abrindo o espaço de interpretação entre o objeto e o indizível. Para ele, "a obra do espírito só existe como ato" e constitui-se como "um discurso que exige e que provoca uma ligação contínua entre a voz que existe e a voz que vem e que deve vir. E essa voz deve ser tal que se imponha e excite o estado afetivo do qual o texto seja a única expressão verbal" (VALÉRY, 2007, p. 185-186).

No tocante à voz, Dominique Maingueneau evoca o conceito de ethé ou etos, da retórica antiga, como sendo as características que os oradores emprestam a si mesmos, implicitamente, "não o que dizem explicitamente sobre si próprios, mas a personalidade que mostram através de sua maneira de se exprimir" (MAINGUENEAU, 2001, p. 137), ou a voz do sujeito enunciador no momento da enunciação.

Maingueneau defende que todo discurso escrito tem a gerir uma relação com uma vocalidade fundamental, "sua relação inelutável com a voz" (MAINGUENEAU, 2001, p. 139). Além disso, a obra seria não apenas sua enunciação, mas sua totalidade material. Assim,

\footnotetext{
24“"Mas aqueles que falham na vida correm também o risco de fracassar no suicídio."

25 "O álcool nos tira da embriaguez. Depois de alguns goles de conhaque, já não penso mais em ti."

26 "[...] tonta de uma embriaguez que ela esperava poder atribuir ao álcool, pois nos recuperamos do vinho mais facilmente que da felicidade."

27 "Estou perto do núcleo misterioso das coisas assim como, à noite, estamos às vezes perto de um coração."

28“"O pêndulo do mundo é o coração de Antígona."

29"Chega sempre um momento em que aprendemos a nos calar, talvez por termos nos tornado, enfim, dignos de escutar [...]." (YOURCENAR, 1974, p. 162)
} 
[...] será preciso levar em consideração as condições da atividade enunciativa. Isso não diz respeito apenas às obras que por alguma "mise en abyme" refletem sua enunciação. Até as ficções que parecem desenvolver-se ignorando sua enunciação organizam-se a partir do tipo de paratopia associado ao posicionamento do escritor no campo literário (MAINGUENEAU, 2001, p. 173).

Segundo Maingueneau, o conceito de paratopia do escritor refere-se a uma localidade paradoxal e diz respeito à "negociação entre o lugar e o não lugar, uma localização parasitária, que vive da própria impossibilidade de se estabilizar" (MAINGUENEAU, 2001, p. 28).

Meschonnic (2007), por sua vez, situa a voz na oralidade, no contínuo corpolinguagem, diferentemente do que acontece com o domínio do signo, em que se opõem som e sentido, em uma divisão binária catastrófica de uma descontinuidade generalizada. Ao contrário, no contínuo, escutamos o sujeito, a voz do sujeito que passa de um sujeito a outro, a voz dentro da qual e por meio da qual o sujeito se constrói. "Um poema é o que nos faz escutar tudo aquilo que não sabemos estar escutando"30 (MESCHONNIC, 2007, p. 149). E isso é a própria teatralidade da voz, a profecia do poema que emerge da voz. Embora Meschonnic refira-se especificamente ao poema, esse conceito pode ser estendido à alma dos textos literários em geral.

Segundo o autor, não é o texto que age sobre essa voz-poema identificada, mas é ela quem escuta e permite que se alcance o poema-texto. De acordo com Meschonnic, os papéis se invertem, numa reversibilidade da escuta em que a voz é transformadora, em que aquilo que se escuta não é o que a voz diz, mas o que a voz faz, "aquilo que ela faz a si mesma, àquele que a emite e, também, aquilo que ela faz àquele que a escuta” ${ }^{31}$ (MESCHONNIC, 2007, p. 150).

Para Meschonnic, o poema é a transformação de uma forma de linguagem em uma forma de vida, e vice-versa, levando-nos a pensar na ideia valeriana de "obra do espírito" (VALÉRY, 2007, p. 185).

\section{« ELLE S'EST COUPÉ LA LANGUE POUR NE PAS RÉvÉLER LES SECRETS QU'ELLE N'AVAIT PAS. $~^{32}$}

Marguerite Yourcenar provoca uma espécie de mise en abyme de vozes, ao criar um jogo entre essa "voz que existe e a voz que vem e que deve vir" (VALÉRY, 2007, p. 185) a partir de "Yourcenar escritora", posicionando sua obra em um pe-

\footnotetext{
30 «[...] un poème est ce qui nous fait entendre tout ce qu'on ne sait pas qu'on entend. » 31 "Ce qu'elle se fait à elle-même, a celui qui la parle, et aussi ce qu'elle fait à celui qui l'entend. " 32 "Ela cortou a própria língua para não ter de revelar os segredos que desconhecia." (YOURCENAR, 1974, p. 109)
} 
ríodo de sua produção; "Yourcenar autora de Feux", demarcando os limites interpretativos e estilísticos em seu prefácio; "Yourcenar persona", expressando, nos pensamentos, subjetividade e passionalidade; e "Yourcenar gnômica", alinhavando as diversas partes da obra de maneira a estruturá-la e emprestando, ao longo das histórias, uma sabedoria omnitemporal a sua persona.

Yourcenar declarou a Matthieu Galey que cada vez mais percebia

que a maneira mais profunda de entrar em um ser ainda é escutando sua voz, compreendendo o próprio canto de que ele é feito. Há uma voz de Adriano [de Memoires d'Hadrien], há uma voz de Zênon [de L'œuvre au noir], e é impossível confundi-las. Trata-se de um certo tom, uma certa maneira de se expressar, de estabelecer as relações entre a pessoa que fala e a pessoa a quem ela fala 33 (YOURCENAR, 1980, p. 68-69).

Cuidemos, pois, de buscar escutar as vozes em sua multiplicidade.

\section{REFERÊNCIAS BIBLIOGRÁFICAS}

CHIRON, B. Le mythe, cet obscur labyrinthe - Brève étude de l'aspect mythologique dans une œuvre de jeunesse de Marguerite Yourcenar, Feux (1935). Angers: Université Catholique de l'Ouest d'Angers, 1993.

CUEVAS, S. L. de. Marguerite Yourcenar - Croquis et griffonisp. Tradução do inglês para o francês por Florence Gumpel. Paris: Éditions Gallimard, Collection "Le Promeneur", 2008.

EVEN-ZOHAR. "The position of translated literature within the literary polysystem. In: Lawrence Venuti. The translator studies reader. Nova York \& Londres, 2000, p.199-204.

FARRELL, C. F.; FARRELL, E. R. Marguerite Yourcenar's Feux: structure and meaning. Kentucky Romance Quarterly, n. 29, p. 25-25. Lexington: University of Kentucky, 1982.

\footnotetext{
${ }^{33}$ « [...] que la manière la plus profonde d'entrer dans un être, c'est encore d'écouter sa voix, de comprendre le chant même dont il est fait. II y a une voix d'Hadrien, il y a une voix de Zénon, et il est impossible de les confondre. II s'agit d'un certain ton, d'une certaine manière de s'exprimer, d'établir ces rapports entre la personne qui parle et la personne à qui elle parle. »
} 
GALABRU, S. Feux, Marguerite Yourcenar, 2013. LA CAUSE LITTÉRAIRE. Disponível em: <http://www.lacauselitteraire.fr/feux-marguerite-yourcenar>. Acesso em: 08/08/2014.

GENETTE, G. Paratextos editoriais. Tradução de Álvaro Faleiros. Cotia: Ateliê Editorial, 2009.

MAINGUENEAU, D. O contexto da obra literária. São Paulo: Martins Fontes, 2001.

MESCHONNIC, H. Étique et politique du traduire. Paris: Verdier, 2007.

PRÉVOT, A-M. Dire sans nommer : Etude stylistique de la périphrase chez Marguerite Yourcenar. Paris: L’Harmattan, 2002.

ROSENFELD, A. Texto/contexto: ensaios. 2 ed. São Paulo: Perspectiva; Brasília: INL, 1965.

VALÉRY, P. "Primeira aula do curso de poética". In: Variedades. Tradução de João Alexandre Barbosa. São Paulo: Iluminuras, 2007.

YOURCENAR, Marguerite. Feux. Paris: Éditions Gallimard, 1974.

Les Yeux ouverts:Entretiens avec Matthieu Galey. Paris: Éditions du Centurion, coll. « Les interviews », 1980. 